Article

Clair Quentin*

\title{
Acceptable levels of tax risk as a metric of corporate tax responsibility: theory, and a survey of practice
}

https://doi.org/10.1515/ntaxj-2019-0001

Received Jul 12, 2018; accepted Sep 13, 2018

\begin{abstract}
Prescribed levels of acceptable tax risk are increasingly used to articulate degrees of corporate tax responsibility, but the theoretical basis for doing so is not well established. This article (i) develops a theory of the relationship between tax risk and tax responsibility and (ii) shows that acceptable levels of tax risk could be used as a meaningful metric for these purposes, provided that the filing positions anticipated from proposed planning are reviewed against the prescribed level of acceptable risk without taking into account any mitigation of the risk factors that are introduced by the planning. Further, the article reviews the evolving tax risk policies of 20 large European companies, showing that while some progress is being made towards meaningful discourse, even the companies with the most well-developed policies are still making their claims in such a way as to conflate socially responsible tax behavior with diligence in implementing antisocial tax behavior.
\end{abstract}

\section{Introduction}

Since 2013, when Vodafone published its ground-breaking Tax Risk Management Strategy, ${ }^{1}$ prescribed levels of acceptable tax risk have been used to articulate degrees of corporate responsibility with regard to tax. In Vodafone's case, the claim was as follows:

The Group aims for certainty on tax positions it adopts but where tax law is unclear or subject to interpretation, written advice or

\footnotetext{
${ }^{\star}$ Corresponding Author: Clair Quentin: Queen Mary University of London London, United Kingdom; Email: d.clair.quentin@gmail.com

1 Available at the time of writing at http://www.vodafone.com/cont ent/dam/sustainability/pdfs/vodafone_tax_risk_management_strateg y.pdf.
}

confirmation will be sought as appropriate to ensure that our position would, more likely than not, be settled in our favour.

Comparable claims have subsequently been made by other companies, and in 2016, the United Kingdom enacted legislation requiring large companies to publish a tax strategy, specifically stipulating that it must include information about "the level of risk in relation to UK taxation that the company is prepared to accept." 2 There appears, therefore, to be a sense, shared between at least some corporate communications executives and some policymakers, that there is a relationship between tax risk and tax responsibility. Or, at the very least, the contexts in which these metrics are being offered or required seems to imply such a relationship: the claims made by companies are often positioned as social responsibility claims, and the UK policy was said by the UK government to be intended to "drive" (and, therefore, impliedly, improve) behavior around tax planning. ${ }^{3} \mathrm{~A}$ theory of this relationship is not, however, to be derived from the literature on tax and corporate social responsibility, ${ }^{4}$ nor is any other genealogy offered for such theory where the relationship is implied.

So what is the relationship between tax risk and tax responsibility? Do claims about the level of acceptable tax risk really articulate anything useful about corporate tax

2 Finance Act 2016 Schedule 19 Para 23.

3 HMRC, Tax administration: large businesses transparency strategy, 9 December 2015, available at https://web.archive.org/web/ 20181018153645/https://www.gov.uk/government/publications/taxadministration-large-businesses-transparency-strategy/taxadministration-large-businesses-transparency-strategy.

4 The literature reviewed in connection with this observations includes Avi-Yonah, Reuven S, "Corporate Social Responsibility and Strategic Tax Behavior”, University of Michigan Law School, 2006; Preuss, Lutz, "Tax avoidance and corporate social responsibility: you can't do both, or can you?", Corporate Governance: The international journal of business in society, 2010, 10(4), 365-374; Sikka, Prem, "Smoke and mirrors: Corporate social responsibility and tax avoidance." Accounting Forum, 2010, 34(3-4), 153-158; Lanis, R. and G. Richardson, "Corporate social responsibility and tax aggressiveness: an empirical analysis”,Journal of Accounting and Public Policy, 2012, 31(1), 86-108; 
responsibility? This article seeks to address those questions.

The principal materials reviewed in this article are statements made by companies (specifically, the corporate tax responsibility claims made by the 20 largest European companies as ranked by income in 2016) regarding their management of tax risk. As regards underlying disciplinary approach, these materials are reviewed from a legal perspective, insofar as they are interpreted as statements made about the behavior of legal subjects vis-àvis legal regimes that apply to them. The interpretation is, however, systematized in accordance with a theoretical framework specifically developed for the purpose of the analysis performed in this article. That framework ultimately derives from existing tax risk management discourse, albeit that existing tax risk management discourse displays a significant omission in this area. The omission is that (as discussed below) the existing discourse elides the mitigation of structural tax risks in a company's transactions or business processes with tax planning intended to reduce tax liabilities. This article introduces the otherwise absent distinction by reference to the author's existing published research in this area: the "risk-mining" theory of tax avoidance (as to which see further below).

The social or ethical source for the corporate obligation to behave responsibly is drawn for the purposes of this

Dowling, G.R., "The curious case of corporate tax avoidance: is it socially irresponsible?”, Journal of Business Ethics, 2013, 124(1), 1-12; Hasseldine, John and Gregory Morris, "Corporate social responsibility and tax avoidance: A comment and reflection”, Accounting Forum, 2013, 37(1), 1-14; Jenkins, Rhys \& Peter Newell, "CSR, Tax and Development”, Third World Quarterly, 2013, 34(3), 378-396; Cerioni, Luca, "International Tax Planning and Corporate Social Responsibility (CSR): Crucial Issues and a Proposed Assessment in the European Union Context”, European Business Law Review, 2014, 25(6), 845-875; Fisher, Jasmine M., "Fairer Shores: Tax Havens, Tax Avoidance, and Corporate Social Responsibility”, Boston University Law Review, 2014, 94 , 337-365; Knuutinen, Reijo, "Corporate Social Responsibility, Taxation and Aggressive Tax Planning”, Nordic Tax Journal, 2014, 1, 36-75; HJI Panayi, Christiana, "Is Aggressive Tax Planning Socially Irresponsible?”, Intertax 2015, 10, 544-558; Ylönen, Matti and Matias Laine, “For logistical reasons only? A case study of tax planning and corporate social responsibility reporting”, Critical Perspectives on Accounting 2015, 33, 5-23; Holland, Kevin, Sarah Lindop and Fatimah Zainudin, "Tax Avoidance: A Threat to Corporate Legitimacy? An Examination of Companies' Financial and CSR Reports”, British Tax Review, 2016, 3, 310; Jones, Stewart, Max Baker and Ben Forrest Lay, "The relationship between CSR and tax avoidance: an international perspective”, Australian Tax Forum, 2017, 32(1), 95-127; and Kiesewetter, Dirk and Johannes Manthey, "Tax avoidance, value creation and CSR - a European perspective", Corporate Governance: The International Journal of Business in Society, 2017, 17(5), 803-821. article from discourse around sustainable development, although, as explained below, the theory adumbrated in this article is agnostic as to how the obligation to behave responsibly is derived-it is concerned with the question whether acceptable levels of tax risk are an adequate metric for the degree to which that responsibility is being discharged.

The structure of the article is as follows. First, after a brief discussion of the background to this research and the sustainable development framing, this article develops a theory of how tax risk and tax responsibility relate, building on existing tax risk management discourse (Section 2). Then, based on that theory, it (i) assesses the utility of tax risk discourse as a basis on which to found a metric of corporate tax responsibility and (ii) elaborates a six-rung "ladder" for assessing the degree to which such discourse, as deployed by any given company, ascends towards making useful claims (Section 3). It goes on to review the corporate tax responsibility claims made by the 20 largest European companies (as ranked by income in 2016) and plots the movement of those companies up the ladder from 2017 to 2018 (Section 4), and, finally, it draws certain conclusions and offers policy recommendations (Section 5).

\section{The relationship between tax risk and tax responsibility}

\subsection{Background: corporate tax behavior and sustainable development}

The research set out in this article forms part of the Sustainable Market Actors: Responsible Trade (SMART) project, an EU Horizon 2020 research program being run by the Faculty of Law, Oslo University. The terms of reference for the SMART project adopt a conception of sustainable development referred to as the "Oxfam Doughnut." In broad summary, the Oxfam Doughnut involves ensuring that all people have the resources needed to fulfill their human rights (food, water, health care, energy, etc.) while ensuring that humanity's use of natural resources does not stress critical Earth-system processes. The inner ring of the doughnut represents minimums of rights fulfillment, and the outer ring represents maximums of Earth-system process stress.

5 K. Raworth, A safe and just space for humanity, Oxfam Discussion Paper, February 2012, available at https://web.archive.org/web/ 20180624164154/https://www.oxfam.org/sites/www.oxfam.org/files/d p-a-safe-and-just-space-for-humanity-130212-en.pdf. 
Applying that conception, this article proceeds on the basis that (within currently prevailing systems of human organization) well-funded public exchequers are necessary for sustainable development. This is most obviously the case in respect of the inner ring, because public infrastructure and services of various kinds are necessary for the realization of economic and social rights, such as the rights to food, water, housing, health, and education. It is also the case in respect of the outer ring, because the combination of underfunded public services, under-provision of public welfare, and under-resourced regulatory regimes is likely to have a variety of consequences with adverse environmental impacts. Clearly, it is also necessary for public revenue to be spent wisely rather than lost to corruption or wasted in bloated military budgets, but this does not undermine the claim that well-funded public exchequers are necessary (albeit not in themselves sufficient) for sustainable development.

The dynamics of the fiscal burden imposed by states on corporate capital is treated as a zero-sum game for the purposes of this article. There is of course a widespread belief that corporate tax cuts can encourage growth and, therefore, increase revenue, ${ }^{6}$ and, conversely, it is sometimes argued that a higher corporate tax take has a positive impact on corporate profits because of the effects of increased public investment, ${ }^{7}$ and (whether they are right or wrong) these arguments are relevant to the development of tax policy. At the level of the direction of travel of an individual unit of revenue accruing to a company once in the hands of that company, however, these arguments are not relevant; that unit of revenue is either paid out in tax, or it is used by the company for other purposes.

It is on that level that the game of corporate financial performance versus public revenue is of a zero-sum nature, and it is played out through the mechanisms of tax risk management, tax planning, tax compliance, tax enforcement and so forth, on a taxpayer-by-taxpayer basis. It follows that, within the context of the statutory tax regime of a specific state, to the extent that specific choices made by companies in playing that "game" can have the effect that less tax is paid, those choices will have an adverse sustainable development impact. Some of those choices will, however, have been encouraged by the state in question (e.g.,

6 See, for example, HM Treasury, Business Tax Road Map, March 2016, available at https://web.archive.org/web/20180624163628/https://ass ets.publishing.service.gov.uk/government/uploads/system/uploads/a ttachment_data/file/509249/business_tax_road_map_final2.pdf.

7 See, for example, The PRI Association, Engagement Guidance on Corporate Tax Responsibility, 2015 https://web.archive.org/web/ 20180624163824/https://www.unpri.org/download?ac=4536. tax reliefs for specific categories of investment), and so the salient agent of the adverse sustainable development impact will in such cases be the state itself.

Other such choices will not have been encouraged by the state in question, and, consequently, the salient agent of the adverse sustainable development impact will in such cases be the company. A core purpose of this article is to set out, and then apply, a theoretical basis for determining objective circumstances in which it is proper to lay responsibility for such adverse sustainable development impact at the door of the company, notwithstanding that the company is operating within a tax system imposed (ultimately through its de jure monopoly over forcible interventions in property relations) by the state.

A more conventional way to frame such an investigation would be to say that it develops and then applies an objective definition of tax avoidance (as opposed to legitimate tax planning, on the one hand, and tax evasion, on the other hand). There is extensive public and academic debate over whether and the extent to which companies not avoiding tax can be formalized as a matter of corporate responsibility, and while it would be outside the scope of this article to review that debate, it is safe to say that a major crux within it is the definitional problem around behaviors that are legal but nonetheless unacceptable. Here the approach (adopting and adapting the "risk-mining" theory of tax avoidance ${ }^{8}$ ) is to address that definitional problem using the conceptual framework of tax risk management, which is the conceptual framework inhabited by behaviors condemned externally as "tax avoidance" when considered internally within the organization.

\subsection{Tax risk management: definitions and assumptions}

Tax activity on the part of companies (which for these purposes includes corporate groups) is referable to work performed by an institutionally distinct tax function. The tax function will be internal personnel with various taxrelated responsibilities, supported by external tax advisers. Viewed from the outside on a "black box" basis, it is sometimes difficult to say of a company's behavior whether it is "tax motivated," but the recommendations of a company's tax function, insofar as they are adopted

8 D. Quentin, "Risk-Mining the Public Exchequer”, Journal of Tax Administration, [S.1.], 3(2), Dec. 2017. ISSN 2059-190X. Available at: <http://JoTA.website/article/view/142/107>. 
by management, may be assumed to have a discrete and determinate institutional genealogy.

The work performed by a tax function falls under a number of labels (these labels are in widespread use among practitioners). Tax compliance means ensuring that tax laws are complied with; this primarily means fulfilling reporting and payment obligations, although it also includes making claims, exercising statutory tax options, and any number of other acts that emanate from the legal relation between taxpayer and tax authority. Tax planning, by contrast, refers to recommendations that a tax function might make as regards the wider behavior of the company (e.g., in the legal structuring of a commercial transaction or a business process), with a view to securing a tax advantage or mitigating a tax risk. Tax controversy refers to the process of responding to tax authority challenge to a position taken by the company in its tax compliance.

It will be readily apparent that the definitions of these activities are suggestive of a process: tax planning recommendations, if adopted, will lead to positions being taken at the tax compliance stage, which might not otherwise have been taken, and those positions might be susceptible to challenge, resulting in a tax controversy situation. In order to mitigate such risk of challenge, the tax planning in question might, therefore, necessitate further tax planning. Tax risk management is an umbrella term for this nexus of intersecting and, in some instances, reflexive processes. As such it operates to a certain extent to obscure some of the distinctions that might be capable of being drawn within it.

In particular, it might be supposed that the mitigation of structural tax risks in the company's transactions or business processes would be treated as distinct from tax planning intended to reduce tax liabilities, but in fact these two tax activities are elided in the nomenclature. For example, in discussion of the "tax control framework" advocated by Robbert Hoyng, Sander Kloosterhof, and Alan Macpherson in Tax Risk Management: from Risk to Opportunity, "where [the authors] refer to risks, a missed opportunity is also seen as a risk." ${ }^{9}$ These opportunities, it is later explained, include "the ability of the organization and the tax function to create value from [...] future tax planning proposals." 10 To emphasize, what is being said here is that tax planning, even in its most aggressive forms,

\footnotetext{
9 Hoyng, R., S. Kloosterhof and A. Macpherson, 'Tax Control Framework', in Bakker, A. and S. Kloosterhof, eds., Tax Risk Management: from Risk to Opportunity, Amsterdam, 2010, 19-70, p.30. 10 ibid p.55
}

is a form of risk mitigation: the mitigation of the risk of missing a tax opportunity.

It is a key contention of this article that this broad concept of "tax risk management" needs to be unpacked and the potential genealogies of tax risk carefully explored, in order for an objective and meaningful taxonomy of corporate tax behavior to be developed. Before doing so, however, it is necessary to define with some specificity what is meant by certain further terms that will be used in the subsequent discussion, and to set out two assumptions that are crucial to the analysis.

Tax risk could include a wide variety of tax-related risks (e.g., reputational risk arising from tax avoidance), but the specific category of tax risk that is relevant to the following discussion is the risk of a tax liability being understated; in other words, the risk of a tax position taken at the tax compliance stage being successfully challenged by a tax authority, having the consequence that additional tax is payable. In other words, "tax risk" is only used here in a sense that implies risk to both the company and the public exchequer; the risk to the company is that it will have to pay more tax, and the risk to the public exchequer is the risk of failing to collect additional tax that may be payable. The concomitant risk to the public exchequer where tax risk exists is referred to as exchequer risk. Prima facie tax risk and exchequer risk are the same risk viewed from two different perspectives, but there is a crucial difference that will be explored in a subsequent section of this article: tax planning that gives rise to tax risk creates, on the quantitative level of potential fiscal impact, more exchequer risk than tax risk.

A feature of a transaction, business structure, or process that gives rise to or increases tax risk is referred to as a tax risk factor. Tax risk factors (so defined) are not introduced at the tax compliance stage. A position taken at the tax compliance stage might be susceptible to challenge without reference to a tax risk factor (e.g., because it contains a computational error or deliberate falsehood) but where a challenge takes place by reference to something falling outside the legal relation between taxpayer and tax authority, that something (the risk factor) is by definition not a feature of the tax compliance. The compliance has merely reflected one available tax analysis of the feature of the transaction, while the tax authority challenge reflects another.

One key assumption underpinning the theory set out in this article is with regard to that analysis adopted at the tax compliance stage. It may be assumed that, as a rule, if a company implements tax planning, it will then proceed to claim the benefit of it (claiming the benefit of it in its entirety if it is an all-or-nothing matter or, to some degree, if 
it is a matter of degree). This may seem obvious but it introduces a subtler dynamic than might first appear, and it is worth pausing to consider its implications. Take, for example, a simple cross-border intragroup transaction entered into without any tax planning. This transaction introduces a risk factor in the form of transfer pricing risk. Now suppose that a tax haven hub entity is inserted between the buyer and the seller. In the context of our definitions, that insertion introduces a tax risk factor notwithstanding that (a) there is already transfer pricing risk even without the insertion and (b) no anti-haven legislation is supposed for the purposes of this illustration. The reason for this is as follows.

Transfer pricing is not an exact science, and it generally yields a range of viable prices, which means it can be manipulated to achieve a tax advantage. In the absence of the tax haven entity, however, a high deduction in the buying entity, while yielding a tax advantage in that entity's jurisdiction, would give rise to a cost in the form of the increased taxable receipt in the other jurisdiction. By the same token, a low taxable receipt in the selling entity would yield a tax advantage in that entity's jurisdiction, but there would be a cost in the form of the decreased deduction in the other jurisdiction. The insertion of the haven entity eliminates both of these costs, and so (on the basis of the assumption regarding claiming the benefits of tax planning) it may be supposed that a greater deduction will be claimed in the buying entity jurisdiction, and a lower taxable receipt will be reported in the selling jurisdiction, than would otherwise be claimed or reported. These filing positions would give rise to an increased transfer pricing risk. And because a tax risk factor is defined as "a feature of a transaction, business structure or process which gives rise to or increases tax risk," the insertion of the haven entity constitutes the introduction of a tax risk factor.

Another key assumption underpinning the analysis in this article is that the company in question is neither committing a crime nor acting negligently on the level of its tax function. The analysis developed in this article is specific to the question of irresponsible tax behavior which cannot easily be characterized as irresponsible on the simple basis that it is, say, criminal or negligent.

\subsection{Categories of tax risk mitigation}

As a matter of process, then, a company (or, as noted above, group) goes about its business, and its tax function will be on the look-out for (a) tax planning opportunities and (b) tax risk factors. Despite being rolled up into a single category of "tax risk management," these are in fact two distinct things to be on the look-out for. The distinction being drawn here is between (a) opportunities to arrange the company's affairs so that less tax is reported payable at the tax compliance stage than would otherwise be reported payable (let us for the time being call this simple tax planning ${ }^{11}$ rather than disguising its character by rolling it up into tax risk mitigation), and (b) proposed arrangements of the company's affairs that give rise to the possibility that more tax will be payable than the company proposes to report at the tax compliance stage, where that possibility can be reduced by implementing those arrangements differently (let us call this simple tax risk mitigation).

At the heart of the distinction between "simple tax planning" and "simple tax risk mitigation" lies a distinction in the direction of travel of the company's intended tax liability mapped against the direction of travel of the company's anticipated tax risk. In the case of "simple tax planning," implementing the tax function's recommendations will yield a reduction in the amount of tax the company reports at the tax compliance stage and no change in the amount of tax risk (see Figure 1a). In the case of "simple tax risk mitigation," by contrast, implementing the tax function's recommendations will yield no change in the amount the company reports at the tax compliance stage; the recommendations will have the aim, rather, of ensuring that the position that would be taken anyway is more robust to tax authority challenge (see Figure $1 b)$.

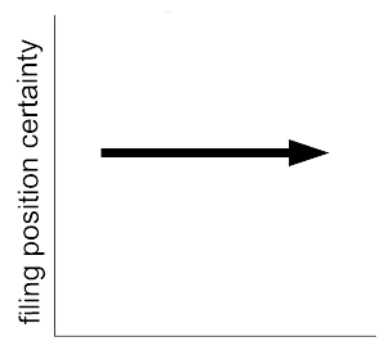

tax saving

(a) Simple tax planning

Figure 1

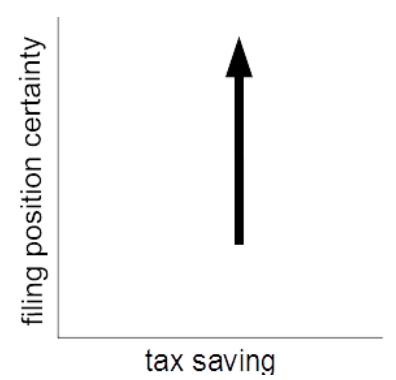

(b) Simple tax risk mitigation
11 The terms defined in the foregoing subsection are (with the possible exception of "exchequer risk," and less narrowly in the case of "tax risk") in general use among tax risk management professionals and commentators. The terms defined in this subsection by contrast, "simple tax planning" and "simple tax risk mitigation," and the term "deliberately created tax risk," which is defined in the subsection which follows, are freshly introduced in this article to label behaviors identified by reference to the theoretical distinctions being drawn here. 
The position is made more complicated, however, by virtue of the fact that tax planning can itself introduce tax risk factors. By virtue of their institutional genealogy, such tax risk factors intersect with both of the tax function activities distinguished above, giving them a distinct character of their own. In the premises the company is proposing to report a reduced tax liability by reference to arrangements recommended by its tax function, but it will do so notwithstanding any risk factors that the arrangements themselves introduce(see Figure 2a).

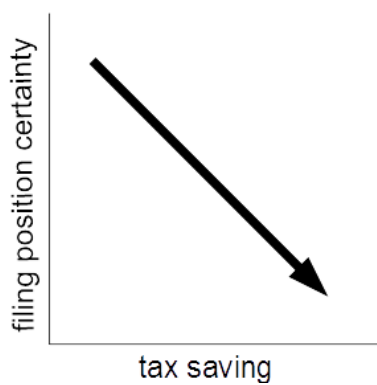

(a) Tax planning introducing a tax risk factor

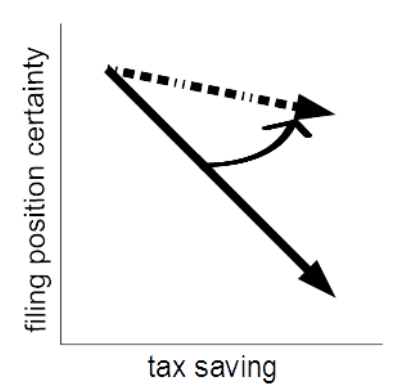

(b) Mitigation of tax risk introduced by tax planning
Figure 2

Of course, these tax risk factors, as with the risk factors mitigated in the case of simple tax risk mitigation, can be mitigated. This would constitute a third category of tax risk mitigation. It is distinct from the mitigation of "missed opportunity" tax risk (i.e., simple tax planning) because it does not yield a reduction in the amount of tax said to be payable at the tax compliance stage (see Figure $2 \mathrm{~b}$ ), and it is distinct from the mitigation of tax risks arising from the company's commercial or other, non-tax-driven arrangements (i.e., simple tax risk mitigation) because the tax risk factors in question arise from arrangements recommended by the company's own tax function. (An example of such risk mitigation might be bolstering the commerciality of an arrangement entered into for tax purposes by positively doing business in a manner consistent with the legal structuring.)

To summarize, there are three distinct pathdependent subcategories of corporate tax risk, each one perhaps best distinguished from the others by how it is mitigated:

(i) "missed opportunity" tax risk, mitigated by tax planning that (a) aims to reduce the amount of tax reported at the compliance stage but that (b) does not introduce any tax risk factors of its own (i.e., simple tax planning; Figure 1a); (ii) tax risk arising from a company's commercial or other non-tax-driven arrangements, mitigated by recommendations from the tax function that do not aim to reduce the amount of tax liability reported at the compliance stage but that are, rather, intended to make the position taken at the compliance stage more likely to succeed on challenge (i.e., simple tax risk mitigation; Figure 1b);

(iii) tax risk arising from tax planning that aims to reduce the amount of tax reported at the compliance stage (Figure 2a), mitigated by additional recommendations from the tax function that do not aim to further reduce the amount of tax reported at the compliance stage but that are, rather, intended to make the position taken at the compliance stage more likely to succeed on challenge (Figure $2 \mathrm{~b}$ ).

This third category might be thought of more simply as the risk of tax planning failing on challenge; the purpose of setting out its precise institutional genealogy in this way is to clarify that it may be treated as a discrete and objective category of corporate tax risk. Its character, however, requires further elaboration, particularly with reference to the legislative context in which it arises. That further elaboration is provided in the following section.

\subsection{Deliberately created tax risk as an unwarranted financial transfer out of the public exchequer}

Clearly, anything a company does that it is not legally required to do is in some sense attributable to the agency of the company, but where a company is acting in response to a risk, it is a reasonable question to consider how the risk arises. Corporate tax behavior is generally said to be a function of the legislative environment in which the company (or group) is operating, and it certainly seems fair as a general rule to attribute to legislative context the existence of tax risk arising from a company's commercial or other, non-tax-driven, arrangements.

In the case of missed opportunity tax risk, insofar as that risk is mitigated by tax planning that (a) aims to reduce the amount of tax reported at the compliance stage but which (b) does not introduce any tax risk factors of its own (i.e., simple tax planning), the existence of that risk can also fairly be attributed to the legislative context in which it arises. After all, legislatures deliberately enact reliefs and tax opportunities to encourage and reward specific kinds of behavior (e.g., reinvestment of corporate profits into research and development) and individual compa- 
nies cannot generally be blamed for the existence of such statutory tax incentives. ${ }^{12}$

The risk of a company's tax planning failing on challenge (i.e., the third category of tax risk identified in the previous section) is, by contrast, deliberately brought into being by the company. This is because (i) tax planning is something that the company chooses to do, and (ii) tax planning that might fail upon challenge cannot be treated as necessarily referable to legislative context on the basis that the legislature intended it.

The second of the foregoing propositions (which is crucial to the theoretical position set out in this article) may be tested by considering how the risk of a company's tax planning failing upon challenge is mitigated. Consider two contrasting instances of the same tax planning: one where the risk of it failing upon challenge has been conscientiously mitigated and another where such risk has been poorly mitigated such that the planning is ineffective. This will be the case where, as commonly happens, tax planning would fail upon challenge if entered into as a purely formal "paper" exercise but would be much more robust to challenge if the substantive commercial activities of the participants are consistent with the formal position. The tax saving achieved in the well-mitigated case as contrasted with the poorly mitigated case will have been achieved not by the planning itself but by the mitigation of the tax risk. By definition, this mitigation activity cannot be something that the legislature intends to subsidize. If it was, we would not be in the present category of tax risk: this would be an instance of poorly mitigated "missed opportunity" tax risk; poorly implemented simple tax planning, in other words.

As the risk of a company's tax planning failing upon challenge is a species of tax risk deliberately brought into being by the company, rather than being more properly attributable to the legislative context, it may be thought of as deliberately created tax risk. This term is derived from the foregoing definitions, assumptions, and analysis, and it does not correspond to any categories in the wider literature regarding corporate tax risk management. If one looks carefully, however, it is possible to discern this category in tax industry discourse; for example, the authors of a blog post on the PwC website wrote as follows:

So where does tax risk originate? Tax risk isn't typically created within the tax function; it happens earlier in the value chain,

\footnotetext{
12 There is a phenomenon whereby exemptions and tax incentives are lobbied for by companies and a related phenomenon whereby companies make targeted tax breaks a condition of inward investment, but these phenomena are outside the theoretical scope of the analysis in this article.
}

with data, and with people making decisions at the front end of the organisation without sufficient understanding of the tax consequences. ${ }^{13}$

The claim in this PwC blog post is that most tax risk is not deliberately created; atypically, however, according to $\mathrm{PwC}$, it might be. It is that allegedly atypical case, where tax risk is created within the tax function, that falls into the category we are concerned with here.

Deliberately created tax risk should be thought of as a financial transfer out of the public exchequer. In order to understand why this is the case, the tax controversy stage (or, more pertinently, the systematic absence of it) requires to be considered. Tax authorities suffer from information asymmetries and resource constraints, with the consequence that only a small minority of uncertain positions taken at the tax compliance stage are challenged. Further, in cases where a position is likely (but not certain) to survive a tax authority challenge, a tax authority may be expected not to challenge it even with adequate resources at its disposal and in full view of the evidence. In the United Kingdom, for example, HM Revenue \& Customs' stated policy provides (perfectly reasonably) that "Where HMRC believes that it is unlikely to succeed in litigation it will, in the majority of cases, concede the issue."14 Indeed, "In general, HMRC will not take up a tax dispute unless the overall revenue flows potentially involved justify doing so" 15 and a dispute that it is likely to lose does not promise much by way of revenue flows.

The foregoing has serious implications as regards the quantifiable fiscal effects of deliberately created tax risk. It was noted above that by definition, where tax risk exists, it brings with it concomitant exchequer risk. The effect of uncertain tax positions going systematically unchallenged is that the exchequer risk is always greater than the tax risk. This is because, under ordinary self-assessment principles, where the position goes unchallenged, the taxpayer keeps the money whether or not such challenge would have been successful. If all uncertain tax positions were challenged, tax risk and exchequer risk would be quantitatively equal.

13 Giovanni Bracco and Robert Gooding, 'Tax risk: Why tax and risk need to speak the same language', pwc.blogs.com, 13 June 2016, available at https://web.archive.org/web/20170315202409/http://pwc. blogs.com/fsrr/2016/06/tax-risk-why-tax-and-risk-need-to-speak-thesame-language.html.

14 HMRC, Litigation and Settlement Strategy, 2017, p.7, available at https://assets.publishing.service.gov.uk/government/uploads/system/ uploads/attachment_data/file/655344/HMRC_Resolving_tax_disputes. pdf archived at https://archive.is/5IMvH.

15 ibid p 17. 
Unchallenged tax positions, by contrast, represent additional free upside for taxpayers in deliberately created tax risk and additional downside for public exchequers. It is for this reason that deliberately created tax risk must be treated as a financial transfer out of the public exchequer and a financial transfer that (as established above) is not one mandated or deliberately made available by the relevant legislation. As such it may reasonably be characterized as antisocial or irresponsible tax behavior: a behavior that a company concerned about its sustainability impact should not indulge in. "Tax avoidance," in other words, but objectively defined by reference to its institutional genealogy within tax risk management frameworks.

\section{Acceptable levels of deliberately created tax risk as a metric of corporate responsibility}

\subsection{The paradox of tax risk mitigation in the context of deliberately created tax risk}

In view of the foregoing, it is no surprise that (as noted in the introduction to this article) a culture is developing whereby prescribed levels of acceptable tax risk are being treated as metrics of corporate tax responsibility. The paradigmatic form of such a metric would be a level of filing position strength below which the tax advantage in question will not be claimed (and, by implication, below which the relevant tax planning will not be implemented).

There is, however, a serious defect in this metric, which relates to the role of tax risk mitigation. It will be recalled that there exist circumstances (and, indeed, in practice, such circumstances are extremely common) where tax planning importing tax risk factors might be likely to fail upon challenge without tax risk mitigation and likely to succeed upon challenge if the deliberately created tax risk is properly mitigated. It will also be recalled that such things as may be done to mitigate the tax risk in question are, by definition, not things that the relevant legislation exists to subsidize (because if they were, it would, as discussed above, be a case of "simple tax planning" rather than deliberately created tax risk). It follows that a filing position that is, say $80 \%$ likely to succeed, could be one of two very different animals from the perspective of responsible tax behavior.

(1) On the one hand, it could be an instance of ordinary mild tax uncertainty, which has arisen in seeking to apply tax legislation to the taxpayer's commercial situation. This uncertainty could impact upon filing position strength where no tax planning is in play, or where some simple tax risk mitigation has taken place in respect of what was originally a greater degree of uncertainty, or where some simple tax planning has taken place in the context of an already existing tax uncertainty. None of this would be abusive conduct on the part of the company.

(2) Alternatively, it could represent tax planning that, without mitigation of the attendant deliberately created tax risk, would have been highly unlikely to succeed, but which has been brought to an $80 \%$ chance of success (i.e., in practice securing the intended tax saving) through the performing of acts that it is not the purpose of the legislature to subsidize. An $80 \%$ likelihood of success could, therefore, arise from tax behavior which is every bit as abusive as high levels of deliberately created tax risk.

It follows that a high prescribed threshold for filing position strength would not (as might be hoped) require companies to eschew tax avoidance above a threshold of aggressiveness but would only require them to implement the avoidance in such a way as to ensure that it is above a threshold of robustness to tax authority challenge. It is very hard to see why companies who comply with such a requirement are any more socially responsible than companies who do not. Indeed (paradoxically), it would be more socially responsible not to mitigate deliberately created tax risk, because this would give tax authorities a better chance of recovering the tax in the event they challenge the planning.

The solution, if we are to use acceptable levels of deliberately created tax risk as a metric of corporate responsibility, is to treat the salient risk threshold in the case of deliberately created tax risk as the risk of the planning failing upon tax authority challenge, without taking into account the extent to which the deliberately created tax risk may be mitigated. Figure 3 illustrates this approach using the diagrammatic scheme adopted in Figures 1 and 2.

It is an approach that also has clear practical benefits, because before implementation, tax advisers are already in a good position to advise on the notional level of risk without mitigation-indeed it is advice along those lines that underpins risk mitigation recommendations. Advising on actual risk, by contrast, requires waiting until the risk mitigation picture on the ground has developed and performing a full forensic review of the facts in all their messy detail. Professional advice as to prospective tax risk ahead of this full picture being available usually proceeds on the basis of assumptions as to the effectiveness of the 


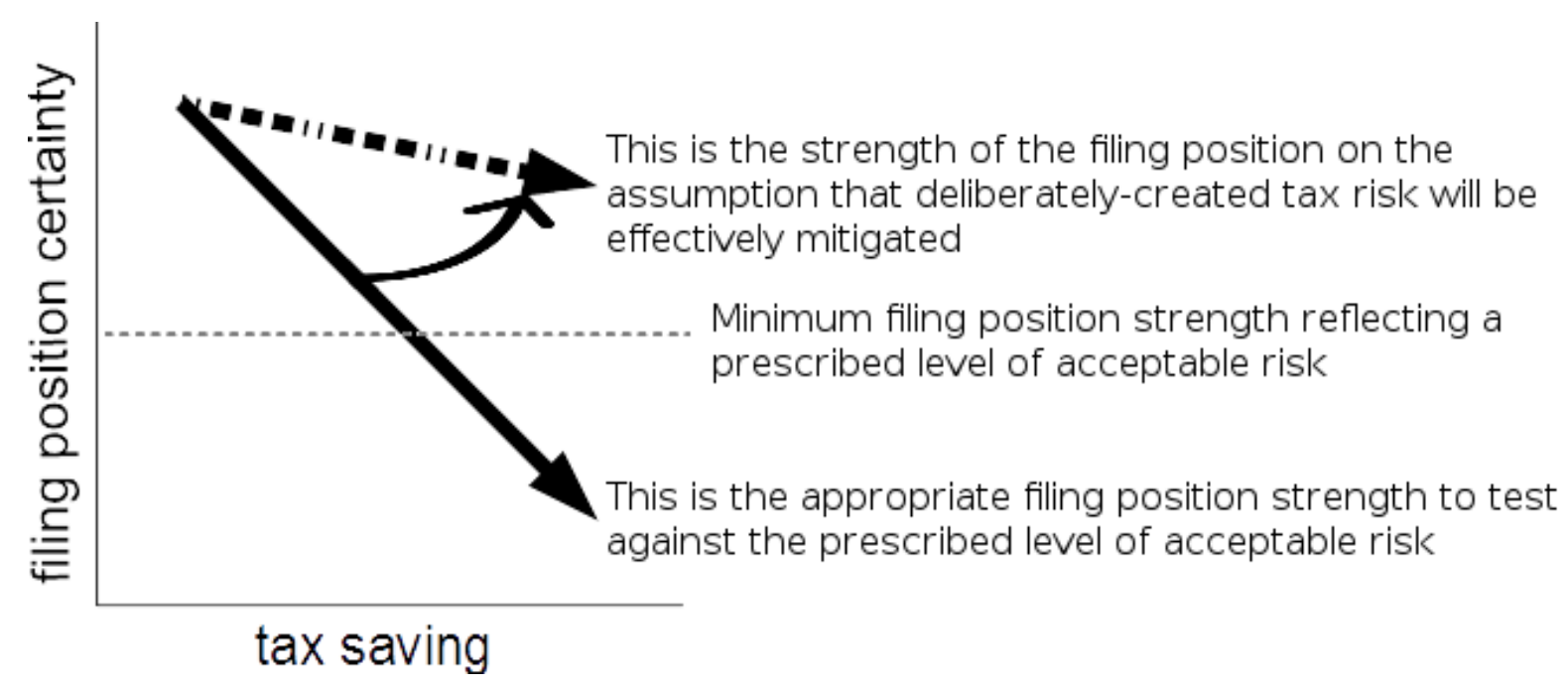

Figure 3: Assessing tax planning which introduces tax risk against a prescribed level of acceptable risk

implementation (including as to adherence to risk mitigation recommendations). In practice, therefore, the level of deliberately created tax risk that is here proposed as being the correct one to test against a responsibility standard does not involve imposing an assumption as to the absence of mitigation; it involves not imposing an assumption as to the effective implementation of such mitigation. It is closer to the perspective of the adviser looking at the proposed planning rather than being more remote.

What is being proposed in practice, therefore, is as follows. Suppose a company has adopted a specified acceptable level of deliberately created tax risk as a metric of corporate tax responsibility. The tax function goes about its business of reviewing the operations of the company, maintaining a look-out for tax risks that require mitigating and tax planning opportunities. In the event that simple tax planning or simple tax risk mitigation is possible, those recommendations can be made without the specified acceptable level of deliberately created tax risk being engaged. But if an opportunity arises to implement tax planning that would introduce tax risk factors (i.e., which would give rise to deliberately created tax risk), at that stage the specified acceptable level of deliberately created tax risk is engaged. The tax function should consider whether the planning would, without any mitigation of those tax risk factors, give rise to a filing position that is sufficiently weak that it would take the company over its acceptable level of deliberately created tax risk insofar as concerns that position. If so (i.e., ignoring the possibility that the tax risk factors introduced by the planning could be mitigated), then the planning should not be recommended.
A company that stated a 50/50 tax risk to be acceptable but applied the threshold in the foregoing manner would be making a far stronger claim as to its corporate tax responsibility than a company that simply only implemented planning that gave rise to $80 \%$ likelihood of success or higher on the basis of the usual assumptions as to proper implementation and effective tax risk mitigation. The former approach eliminates from the reckoning the extent to which the company (to put the point at its simplest) implements its tax avoidance diligently. Obviously, shareholders want tax avoidance to be implemented so that it is maximally robust to challenge, but the extent to which the company achieves this should not form part of any metric for how responsibly the company is behaving as a corporate citizen.

\subsection{The tax risk management discourse "ladder"}

On the basis of the foregoing analysis, and in view of the kinds of responsibility claims made by companies deploying the terms of tax risk management discourse (as to which see below), it is possible to develop a six-rung "ladder" for assessing the degree to which such discourse, as deployed by any given company, ascends towards making useful claims. To be clear, this ladder is not an ex ante hierarchy of possible deployments of tax risk management discourse in a tax responsibility context-it arises from a process of grouping the actual claims made by the subject companies by reference to shortcomings they have in common (as discerned through the lens of the theoretical framework set out above) and then ranking these group- 
ings by reference to their proximity to the condition of making meaningful claims within the theoretical framework set out above.

Rung 1: The existence of tax risk (other than reputational risk) is acknowledged as a corporate responsibility concern.

Rung 2: It is acknowledged that uncertain filing positions might be knowingly taken.

Rung 3 : It is claimed that the organization might choose not to adopt a transaction or structure if the risk is too great.

Rung 4: It is acknowledged that risk factors leading to the possibility of a tax position failing upon tax authority challenge may be introduced by the organization's own tax function, distinguishably from the tax risk factors that are referable to other origins (i.e., the possibility of deliberately created tax risk is acknowledged).

Rung 5: An express threshold applies in the specific circumstances where the risk factor in question would be the one introduced by the organization's own tax function (i.e., there is a prescribed maximum level of deliberately created tax risk).

Rung 6: It is recognized that the appropriate risk level to measure against that threshold in the case of deliberately created tax risk is the risk of the planning failing upon tax authority challenge, without taking into account the extent to which the deliberately created tax risk may be mitigated.

\section{Review of the 20 largest European companies' corporate tax policy statements}

\subsection{Sample selection and review methodology}

The following section interrogates the published tax policies of 20 large European companies. The companies selected are the top 20 companies, as ranked by income, and listed as headquartered in Europe (in practice either European Economic Area states or Switzerland; all are single market states if not EU members), in Fortune Magazine’s "Fortune Global 500" for 2016.16 The search for

16 https://web.archive.org/web/20170321111557/http://beta.fortune. com/global500/list/. relevant material has involved (a) searching the name of the company on Google in combination with the phrases "tax transparency," "tax sustainability," "tax responsibility," "tax policy," "tax risk," "tax strategy," and "tax code of conduct”; (b) browsing the company's website for sustainability or responsibility statements relating to tax: and (c) where these methods do not yield any discussion of tax risk, searching the company's most recent annual report for the phrase "tax risk." This exercise was conducted twice, once between March 12 and 21, 2017 and again between June 19 and 24, 2018. The results from the 2018 review are deployed to arrange the companies on their respective "rungs" on the tax risk management discourse "ladder" for the purposes of the primary review in this section. The results of the previous 2017 review are used for the purposes of diachronic comparison against the 2018 results in the final subsection.

It may be noted that the two search windows straddle the coming into effect of the already noted UK legislation requiring certain companies to publish tax strategy information. As strategies published in compliance with this obligation are specific to the United Kingdom, they do not necessarily constitute the tax strategy of the group as a whole. In cases where there is more information or different information that is specific to the United Kingdom, that information may be noted for added qualitative texture but does not inform the position of the company on the "ladder." In other cases, the UK strategy is effectively expressed to apply group wide.

\subsection{Rung 0: not on the ladder}

In the case of 6 of the 20 companies, no group-level material was found in either in 2017 or 2018, acknowledging that tax risk is a corporate responsibility concern. These companies are EXOR, BNP Parisbas, BMW, HSBC, Siemens, and Carrefour. BNP Parisbas, BMW, HSBC, and Siemens had UK-specific tax strategies addressing questions of tax risk in 2018, however, and a major subsidiary of EXOR i.e. Fiat Chrysler did address tax risk in a published policy ${ }^{17}$ even though its parent did not.

HSBC's UK Tax Strategy ${ }^{18}$ is notable for its unabashedly high appetite for tax risk; it contains the follow-

\footnotetext{
17 https://web.archive.org/web/20170321110739/https://www.fcagrou p.com/en-US/sustainability/FiatDocuments/TAX_Policy_2015_FCA.PD F.

18 https://web.archive.org/web/20180624082222/https://www.hsbc.co $\mathrm{m} /$-/media/hsbc-com/investorrelationsassets/financial-and-regulat ory-reports/171215-hsbc-approach-to-tax.pdf.
} 
ing claim regarding acceptable levels of tax risk: "HSBC does not have any appetite for breaching tax laws or allowing customers to use its services to evade tax." In other words, its appetite for tax risk falling short of formal illegality is unbounded, implying that a filing position with only the most strained arguments to recommend it is nonetheless acceptable.

\subsection{Rung 1: tax risk acknowledged as a corporate responsibility concern}

The largest group among the 20 companies are the 7 companies on rung 1 , that is, those who (broadly speaking, and insofar as concerns group-level responsibility) only go so far as to acknowledge tax risk in general as a corporate responsibility concern: Volkswagen, Daimler, Total, Allianz, Société Générale, ENI, and Tesco (supplemented in the case of Volkswagen, Société Générale, and Tesco by a UK-specific tax strategy document).

A typical set of claims for a company on this rung might be the following claims made by Volkswagen:

A risk management system helps ensure that taxes and duties are shown correctly in the annual financial statements and that the prescribed standards are duly monitored. The Corporate Taxation department and the Taxation departments of the parent companies of the sub-groups monitor compliance with the disclosure obligations of their companies at regular intervals. This monitoring process is supported by regular tax reviews. The Group companies are under obligation to actively comply with the reporting requirements that ensue from the risk management system. ${ }^{19}$

Daimler goes further and acknowledges that what tax risk means in practice is the possibility of litigation. It seems keen to imply that it is primarily change of law risk that it has in mind, however, rather than acknowledging that it might knowingly adopt less-than-certain filing positions (which would have raised them to rung 2):

Daimler AG and its subsidiaries operate in many countries worldwide and are therefore subject to numerous differing statutory provisions and tax audits. Within the Group, the tax assessments of several years are not yet final. Changes in local tax legislation and court verdicts, and differing interpretations by the fiscal authorities in the various jurisdictions - especially in the field of cross-border transactions - can lead to negative effects on the Group's net profit and cash flows. Any changes or interventions

19 https://web.archive.org/web/20170320221458/http://sustainability report2014.volkswagenag.com/sites/default/files/dd_online_link/en/1 9_Policy_on_Taxation_and_Customs_Duties-Synopsis\%20.pdf. by the fiscal authorities are continuously monitored by the Tax department and measures are taken if required..$^{20}$

Companies on this rung might make claims about seeking to "minimize" tax risk. ENI, for example, claims as follows:

ENI wishes to reduce tax risk to a minimum and, to this purpose, we have specific controls aimed at ensuring accuracy and timeliness of settlement and payment of taxes, in the context of transparent and accurate compliance aimed also at the prevention of possible disputes. $^{21}$

Total even goes so far as to tie this aversion to risk to an express policy of not aggressively avoiding tax:

Our tax policy's prime focus is certainty, as our investments are capital intensive and long term. We believe that the expected short term tax benefit derived from artificial or aggressive tax planning will often be outweighed by the reputational and future tax litigation risks inherent in such schemes. ${ }^{22}$

These claims are, however, too vague. In ENI's case, it is not credible that a large multinational company would manage its tax risk wholly out of existence, even if it could, and so it is hard to attribute any substantive meaning to the idea of "minimizing" risk. In Total's case, a strict reading attaching significance to the word "often" (i.e., not necessarily in every case) would imply acknowledgment that Total sometimes does in fact deliberately create tax risk (taking it to rung 4), but the passage as a whole creates ambiguity by reading so as to run counter to that implication.

The only movement between 2017 and 2018 represented by this group is in the case of Société Générale, which was a rung 0 company in 2017 but had made some public claims about tax risk management by the time of the 2018 review. ${ }^{23}$

20 https://web.archive.org/web/20170321105021/https://www.daimle r.com/documents/investors/reports/annual-report/daimler/daimlerir-annualreport-2016.pdf.

21 https://web.archive.org/web/20180622103853/https://www.eni.com /en_IT/sustainability/integrity-human-rights/tax-strategy.page.

22 https://web.archive.org/web/20180621082126/https://www.sustain able-performance.total.com/en/business-ethics-0.

23 https://web.archive.org/web/20180622083606/https://www.societ egenerale.com/sites/default/files/documents/Code\%20de\%20condui te/Tax_Code_of_Conduct_of_Societe_Generale_group_UK.pdf. 


\subsection{Rung 2: acknowledgment that uncertain filing positions might knowingly be taken}

The two companies on rung 2, Royal Dutch Shell and Axa, are further up the discourse ladder by virtue of their acknowledgment that uncertain tax positions might be taken knowingly. This is in contrast to (and in practice in addition to) matters such as compliance error or change of law risk, which are identified as concerns by companies on rung 1. In the case of Royal Dutch Shell (a rung 1 company in 201724), the 2018 acknowledgment that it accepts or "does not fully seek to mitigate" some tax risk is very clear and frank:

Shell supports efficient, predictable and stable tax regimes that incentivise long-term investment. We expect the laws to be applied consistently, creating a level playing field for all. However, Shell operates in more than 70 countries that have differing degrees of political, legal, and fiscal stability. This exposes us to a wide range of political developments that could result in changes to contractual terms, laws, and regulations. Developments in clude additional taxes, windfall taxes, restrictions on deduction and retroactive tax claims.

Shell has a variety of processes for obtaining assurance on the adequacy of tax risk management and internal control, and implements a broad array of measures to manage its tax risks. There are also risks that Shell accepts or does not seek to fully mitigate. ${ }^{25}$ [My emphasis]

Axa's statement to this effect is somewhat more oblique:

We take tax positions that we believe are correct and reasonable in the course of our business. However, there is no guarantee that our tax positions will be upheld by the relevant tax authorities. ${ }^{26}$

If this was expressed as "correct" rather than "correct and reasonable," then it would not constitute an acknowledgment that uncertain tax positions might be taken knowingly. The inclusion of the much lower standard of reasonableness, however, seems sufficient for the purposes of this rung, and in the context of the reasonableness standard, the word "correct" is susceptible to be read as not adding very much to the claim. If the reasonableness standard were offered without the ambiguity introduced by the word "correct," Axa would be a rung 4 company.

24 https://web.archive.org/web/20170312223915/http://www.shell.co $\mathrm{m} /$ sustainability/transparency/revenues-for-governments.html. 25 https://web.archive.org/web/20180618161424/https://www.shell.co $\mathrm{m} /$ sustainability/transparency/shells-approach-to-tax.html. 26 https://web.archive.org/web/20180621130159/https://group.axa.co m/en/about-us/tax-strategy.

\subsection{Rung 3: filing positions not adopted if the risk is too great}

The tax responsibility claims of companies on rung 3 raise the possibility that uncertain tax positions might be considered and either adopted or not adopted depending on the degree of risk in question. In principle, this could mark a substantive engagement with the practical reality of tax risk management, as contrasted with the ambiguous claims about eschewing "artificial" or "aggressive" schemes and "minimizing" risk that are to be found on rung 1. In practice, however, the two companies on this rung (BP and E.ON) are there because they express their statutory UK tax strategies to be applicable group-wide (or at least aligned with group-wide policy), and the UK legislation in this regard mandates that there be a discussion of acceptable levels of tax risk. In both cases, the actual discussion is entirely insubstantial. For example, BP says

We do not prescribe acceptable levels of tax risk. We seek clarity within the law and evaluate the potential tax outcomes of our business transactions and we escalate tax risks and uncertainties to the relevant level within BP to determine the appropriate management response. ${ }^{27}$

In E.ON's case, the rung 3 ranking is even more fragile. The material on this topic in E.ON's tax strategy statement ${ }^{28}$ is vague, and the company's claim to the effect that uncertain tax positions might be considered and then either adopted or not adopted depending on the degree of risk in question is essentially a matter of inference crystallized by the heading "level of tax risk accepted.” It reads as follows:

\footnotetext{
Attitude towards tax planning

When considering the structure of our commercial activities, we take account of a number of factors including consideration of the tax laws of the countries in which we operate. We do not take an unreasonable stance on our interpretation of tax legislation and we strive to work within both the letter and spirit of local laws.

We embrace the E.ON SE Group's Tax Guidelines ${ }^{29}$ and we do not engage in aggressive tax planning and do not participate in artificial tax avoidance schemes to reduce our UK tax liability. Any tax planning undertaken by us will have commercial and economic substance, and we will have regard to the potential impact on our reputation and broader goals.
}

27 https://web.archive.org/web/20180619162529/https://www.bp.com /content/dam/bp/en/corporate/pdf/sustainability-report/group-re ports/bp-approach-to-tax.pdf.

28 https://web.archive.org/web/20180621124405/https://www.eonene rgy.com/About-eon/corporate-responsibility/our-responsibility/taxstrategy-disclosure.

29 These guidelines are seemingly not published. 


\section{Level of tax risk accepted}

The scale and complexity of our business and therein the volume of our tax obligations, means that inevitably risks will arise. We ensure that where risks do arise, they are identified, evaluated and managed proactively to be within the overall E.ON SE Group's Tax Guidelines.

For certain transactions where there is a material level of uncertainty or complexity, we will seek external advice to help reduce risk. Based on the dedication and skills of our tax teams, we will apply professional diligence and care in all our actions in relation to tax matters.

BP was a rung 1 company in $2017^{30}$ and E.ON was not on the ladder at all.

\subsection{Rung 4: the possibility of deliberately-created tax risk is acknowledged}

The sole company on rung 4 is Glencore. Glencore's statement about its tax behavior as accessed in $2017^{31}$ did not address the concept of tax risk in any way, but in the 2018 review, it has leapt to rung 4 by (impliedly at least) acknowledging that risk factors leading to the possibility of a tax position failing on tax authority challenge may be introduced by its own tax function, distinguishably from the tax risk factors that are referable to other origins (i.e., the possibility of deliberately created tax risk is acknowledged). Its tax policy as accessed in $2018^{32}$ contains extensive discussion of tax risk, but the key statements (in different sections of the document) are as follows:

As tax legislation is often complex and its application may be unclear, it is impossible to ensure that our interpretation of our obligations will always be accepted by tax authorities.

And

Glencore may seek to take steps to procure advantage of reliefs and incentives available under applicable laws and double tax treaties.

The wording regarding "seeking" to take steps to procure a tax advantage, in the context of a concession that a tax

30 https://web.archive.org/web/20170320222505/http://www.bp.com/ content/dam/bp/pdf/sustainability/group-reports/bp-approach-totax.pdf.

31 https://web.archive.org/web/20170312225218/http://www.glencore. com/public-positions/tax-transparency/.

32 https://web.archive.org/web/20180620193934/http://www.glencor e.com/dam/jcr:21be94ea-49c6-43df-b3d8-10dc7070ad6f/Group-TaxPolicy-2017-web.pdf. authority may not accept such interpretations as are advanced, is understood as the acknowledgment in question.

\subsection{Rung 5: prescribed maximum level of deliberately created tax risk}

The remaining two companies, Assicurazioni Generali and Nestlé, are on rung 5 by virtue of their prescribed maximum levels of deliberately created tax risk (or, alternatively, minimum filing position strength). In the case of Assicurazioni Generali, formerly a rung 0 company, ${ }^{33}$ its position near the top of the ladder is found on its statutory UK tax strategy, ${ }^{34}$ but that strategy is expressed to be "consistent with the management of risk across [...] the organisation as a whole" and it contains the following claim:

The UK tax authorities and other tax regimes often include tax credits or exemptions for commercial business activity. Where relevant we will seek to claim these incentives if they are consistent with the commercial objectives of the business and do not create significant risk. [My emphasis]

As regards Nestlé, a 2016 document with the title "Nestlé Group Tax Management Principles \& Strategy" was accessed in $2017^{35}$ and continued to be available in 2018. It provides as follows:

We do not take tax positions that are not defendable under full disclosure. We do not engage in tax evasion, artificial or high risk transactions. We do not adopt tax schemes, based on form without commercial substance. We do not use offshore entities that lack business purpose and substance. We do not use hybrid instruments and entities that result in tax avoidance and double deduction. [My emphasis]

\subsection{Rung 6: recognition of the adverse role of tax risk mitigation in the context of deliberately created tax risk}

None of the companies in the survey made it to the top of the ladder. It must, therefore, be supposed that the various risk thresholds we have encountered are applied to prospective filing positions on the assumption that all

33 https://web.archive.org/web/20170313172137/http://www.generali. com/our-responsibilities/responsible-business/tax-payments. 34 https://web.archive.org/web/20180622093730/https://www.genera li.co.uk/About-Us/Generali-UK-Branch-Tax-Strategy.html.

35 https://web.archive.org/web/20170321141046/http://www.nestle.co m/asset-library/Documents/Library/Documents/Corporate_Social_Res ponsibility/Nestle-Tax-Management-Principles-Strategy-2016.pdf. 
the tax risk that has been deliberately created will be mitigated to the maximum extent possible. As discussed above, this renders those risk thresholds meaningless for the purposes of assessing a company's degree of corporate tax responsibility: these companies are conflating socially responsible tax behavior with diligence in implementing anti-social tax behavior. The threshold should be applied to deliberately created tax risk in the absence of any intended mitigation, thereby (in essence) eliminating from the reckoning the effectiveness of the company's implementation of tax avoidance.

\subsection{Progress up the ladder between 2017 and 2018}

It should be emphasized that there is a degree of subjectivity to the foregoing rankings, and the view could reasonably be taken that some companies have been given the benefit of interpretative doubt, while others have not. In addition, as already noted, the 2017 and 2018 reviews straddle the coming into effect of the UK legislation regarding tax strategies, which skews the comparison between the two reviews. Figure 4 is nonetheless offered as an illustration of the overall direction of travel in the development of this discourse.

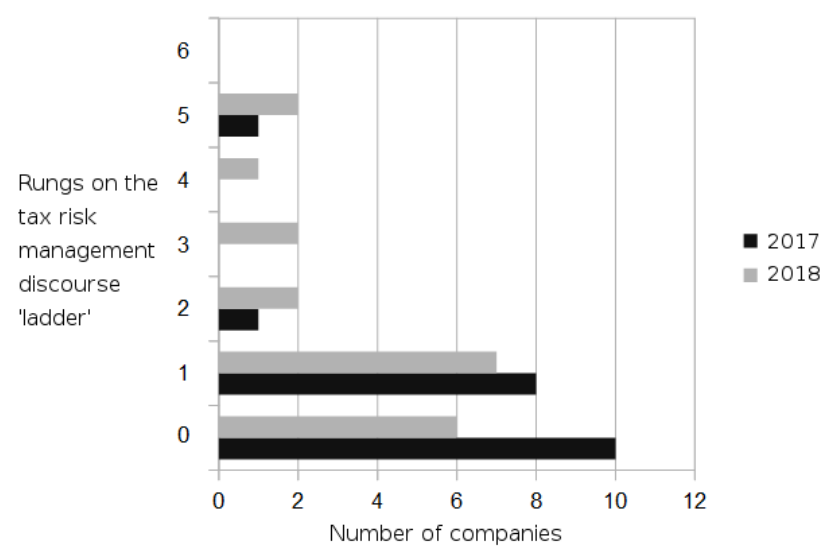

Figure 4: Comparison of 2017 and 2018

\section{Conclusions and policy recommendations}

In conclusion, progress is being made towards converging the discourse around corporate tax responsibility, on the one hand, and corporate tax risk management discourse, on the other hand, but there exists a major obstacle insofar as purportedly responsible tax behavior currently includes effective mitigation of deliberately created tax risk. In other words, we are treating companies as if they are behaving responsibly insofar as they procure financial transfers from public exchequers diligently. Acceptable levels of tax risk could be used as a meaningful metric for corporate tax responsibility, provided that the filing positions anticipated from proposed tax planning are reviewed against the prescribed level of acceptable risk without taking into account any mitigation of the tax risk factors that are introduced by the tax planning.

The UK legislation requiring companies to publish tax risk strategies has moved the discourse on to a certain extent, but the legislation could be improved by introducing a much more specific set of requirements about how the risk threshold should be expressed and applied, along the lines discussed in the foregoing paragraph. The European Union could usefully enact legislation imposing similar obligations, provided that it too imposes a much more specific set of requirements along those lines.

\section{References}

Avi-Yonah, Reuven S, “Corporate Social Responsibility and Strategic Tax Behavior”, University of Michigan Law School, 2006, available at https://web.archive.org/web/20181018123828/https://reposi tory.law.umich.edu/cgi/viewcontent.cgi?referer=\&httpsredir $=1 \& \mathrm{a}$ rticle $=1066 \&$ context=law_econ_archive

Bracco, Giovanni, and Robert Gooding, 'Tax risk: Why tax and risk need to speak the same language', pwc.blogs.com, 13 June 2016, available at https://web.archive.org/web/20170315202409/http://pw c.blogs.com/fsrr/2016/06/tax-risk-why-tax-and-risk-need-to-sp eak-the-same-language.html

Cerioni, Luca, “International Tax Planning and Corporate Social Responsibility (CSR): Crucial Issues and a Proposed Assessment in the European Union Context”, European Business Law Review, 2014, 25(6), 845-875

Dowling, G.R., "The curious case of corporate tax avoidance: is it socially irresponsible?", Journal of Business Ethics, 2013, 124(1), 1-12

Fisher, Jasmine M., "Fairer Shores: Tax Havens, Tax Avoidance, and Corporate Social Responsibility", Boston University Law Review, 2014, 94, 337-365

Hasseldine, John and Gregory Morris, "Corporate social responsibility and tax avoidance: A comment and reflection", Accounting Forum, 2013, 37(1), 1-14

HMRC, Litigation and Settlement Strategy, 2017

HM Treasury, Business Tax Road Map, March 2016

Holland, Kevin, Sarah Lindop and Fatimah Zainudin, "Tax Avoidance: A Threat to Corporate Legitimacy? An Examination of Companies' Financial and CSR Reports", British Tax Review, 2016, 3, 310 
Hoyng, R., S. Kloosterhof and A. Macpherson, 'Tax Control Framework', in Bakker, A. and S. Kloosterhof, eds., Tax Risk Management: from Risk to Opportunity, Amsterdam, 2010

HJI Panayi, Christiana, "Is Aggressive Tax Planning Socially Irresponsible?", Intertax 2015, 10, 544-558

Jenkins, Rhys \& Peter Newell, “CSR, Tax and Development”, Third World Quarterly, 2013, 34(3), 378-396

Jones, Stewart, Max Baker and Ben Forrest Lay, "The relationship between CSR and tax avoidance: an international perspective", Australian Tax Forum, 2017, 32(1), 95-127

Kiesewetter, Dirk and Johannes Manthey, "Tax avoidance, value creation and CSR - a European perspective", Corporate Governance: The International Journal of Business in Society, 2017, 17(5), 803821

Knuutinen, Reijo, “Corporate Social Responsibility, Taxation and Aggressive Tax Planning”, Nordic Tax Journal, 2014, 1, 36-75
Lanis, R. and G. Richardson, "Corporate social responsibility and tax aggressiveness: an empirical analysis”, Journal of Accounting and Public Policy, 2012, 31(1), 86-108

PRI Association, Engagement Guidance on Corporate Tax Responsibility, 2015

Preuss, Lutz, "Tax avoidance and corporate social responsibility: you can't do both, or can you?", Corporate Governance: The international journal of business in society, 2010, 10(4), 365-374

Quentin, D., “Risk-Mining the Public Exchequer”, Journal of Tax Administration, [S.I.], 3(2), Dec. 2017

Raworth, K., A safe and just space for humanity, Oxfam Discussion Paper, February 2012

Sikka, Prem, "Smoke and mirrors: Corporate social responsibility and tax avoidance." Accounting Forum, 2010, 34(3-4), 153-158

Ylönen, Matti and Matias Laine, "For logistical reasons only? A case study of tax planning and corporate social responsibility reporting", Critical Perspectives on Accounting 2015, 33, 5-23 